\title{
A utilização dos recursos tecnológicos no ensino e aprendizagem de língua inglesa
}

\author{
The use of technological resources in teaching and \\ learning English
}

\author{
Daiane Signor de Souza ${ }^{1}$ \\ Lucilene Bender de Sousa²
}

\begin{abstract}
Resumo
Os recursos tecnológicos vêm provocando importantes mudanças na educação e adquirindo cada vez mais espaço em sala de aula. Diante dessas transformações, este artigo tem o objetivo de investigar como os recursos tecnológicos podem auxiliar no processo de ensino e aprendizagem de inglês como língua adicional através da pesquisa bibliográfica. Os inúmeros sites e aplicativos encontrados podem ser usados para desenvolver habilidades comunicativas específicas ou para o trabalho com a língua de forma integral. No entanto, para que haja um melhor aproveitamento desses recursos, é imprescindível que o professor se coloque na posição de mediador, conheça e use essas ferramentas, bem como incentive a autonomia dos seus alunos de forma que possam complementar o ensino com as atividades on-line fora da sala de aula. Nesse contexto, 0 professor exerce papel fundamental, guiando os alunos na aprendizagem da língua e na exploração de ferramentas tecnológicas que oportunizam a eles maior autonomia e responsabilidade na construção do conhecimento.
\end{abstract}

Palavras-chave: Recursos tecnológicos. Ensino e aprendizagem de inglês. Mediação.

\begin{abstract}
Technological resources have been causing important changes in education and increasingly acquiring space in the classroom. Given these transformations, this article aims to investigate how technological resources can assist in the process of teaching and learning English as a second language through bibliographic research. The numerous websites and applications found can be used to develop specific communicative skills or to work with integrated language skills. However, in order to make better use of these resources, it is essential that the teacher adopts the position of mediator, knows and uses these tools, and encourages the autonomy of their students so that they can complement the teaching with online activities. In this context, the teacher plays a fundamental role in the process of acquiring a new language, guiding the students in the learning of the language and exploration of the technological resources which provide practice them more autonomy and responsibility in the construction of the knowledge.
\end{abstract}

Keywords: Technological resources. Teaching and learning English. Mediation.

\section{Introdução}

Ao longo dos anos, a tecnologia vem adquirindo cada vez mais espaço nas salas de aula. Além de estar presente nos processos de ensino e aprendizagem, é utilizada como meio de comunicação e interação entre professores e alunos. Os recursos tecnológicos podem tornar a escola um ambiente mais

\footnotetext{
1 Especialista em Ensino, Linguagens e suas Tecnologias pelo Instituto Federal de Educação, Ciência e Tecnologia, campus Ibirubá, RS, Brasil. Orcid: https://orcid.org/0000-0003-4789-5289 E-mail: daianesignorsz@gmail.com

2 Doutora em Linguística. Instituto Federal de Educação, Ciência e Tecnologia do Rio Grande do Sul, Farroupilha, RS, Brasil. Orcid: https://orcid.org/0000-0002-3833-5987 E-mail: lucilene.sousa@farroupilha.ifrs.edu.br
}

LínguaTec, Instituto Federal de Educação, Ciência e Tecnologia do Rio Grande do Sul, Bento Gonçalves v. 6, n. 1, p. 16-33, jun. 2021. 
atrativo e interessante, transformando o modo como adquirimos e compartilhamos os nossos conhecimentos e contribuindo para auxiliar no desenvolvimento das aprendizagens dos alunos.

Para que a aprendizagem ocorra, é fundamental que seja contextualizada no âmbito da realidade dos estudantes, tornando os conteúdos aprendidos significativos. Usar a tecnologia para ensinar é uma forma de nos aproximarmos da realidade dos estudantes que, cada vez mais, estão imersos no mundo virtual. 0 grande desafio dos professores, mais do que utilizar os recursos tecnológicos, é traçar princípios que privilegiem a construção de conhecimentos, o aprendizado significativo, interdisciplinar e integrador. Isso só é possível se assumirem uma posição de mediadores das interações que ocorrem em sala de aula, procurando meios que estimulem o interesse e engajamento de seus alunos.

Trabalhar com as mídias ainda é um desafio para boa parte dos professores. A sua inserção em sala de aula requer grandes mudanças pedagógicas e de postura frente ao conteúdo, tanto por parte dos docentes, quanto por parte dos discentes (BARBOSA, 2012). Entretanto, com a rápida difusão dos avanços tecnológicos, a escola não pode ignorar a necessidade de se adequar ao desenvolvimento tecnológico e as possibilidades de utilizar a tecnologia como uma ferramenta para a aprendizagem.

No caso do ensino de idiomas, em especial da língua inglesa, novas tecnologias podem ser grandes aliadas, propiciando práticas educativas integradas a várias mídias, tornando os conteúdos mais atraentes para o aluno (LOPES, 2012). É necessário rever o modo como se pensa o ensino de língua inglesa no contexto escolar, repensar e redesenhar tanto as práticas pedagógicas como os currículos, incorporando as tecnologias em seu ambiente.

Para Beaugrande (2002), a tecnologia sempre se fez presente na educação para facilitar a apresentação da informação. $O$ autor ressalta que, comparados aos tradicionais espaços para o ensino da língua inglesa, os atuais laboratórios informatizados oferecem aos aprendizes um ambiente mais rico para a aquisição da língua.

Diante das mudanças provocadas pelas tecnologias, cabe ao professor compreender esse novo contexto e usá-lo a favor da escola. Sendo assim, o presente artigo tem como objetivo identificar, por meio da pesquisa bibliográfica, como os recursos tecnológicos podem auxiliar no processo de ensino e aprendizagem do inglês como língua adicional. Este artigo estrutura-se a partir de três focos principais: recursos tecnológicos e habilidades comunicativas, o papel do professor mediador e aprendizagem autônoma. 


\section{Recursos tecnológicos e habilidades comunicativas: leitura e escrita, fala e audição}

Com o surgimento e avanço das Tecnologias da Informação e Comunicação (TICs), a rapidez das informações modificou o modo de pensar e de viver das pessoas. Em relação à educação, novas maneiras de ensino e aprendizagem surgiram, exigindo uma nova postura dos profissionais, principalmente, dos que atuam na sala de aula, lidando diretamente com crianças e jovens movidos pela tecnologia.

Neste mundo digital e sem fronteiras, a língua inglesa adquire status de língua franca. Crystal (2003) ressalta a importância da língua inglesa ao classificá-la como a língua universal utilizada por milhões de falantes ao redor do mundo. Partindo desse pressuposto, faz-se necessária uma constante pesquisa sobre o processo de ensino e aprendizagem do inglês, bem como da importância dos recursos tecnológicos no contexto formal e informal de aprendizagem. Para Morin:

[...] a primeira tecnologia a revolucionar 0 ensino de línguas foi o livro, a segunda foi a gravação em áudio, com a criação do fonógrafo e seus desdobramentos até chegar aos gravadores portáteis e depois aos CDs. Em seguida foi a vez da tecnologia em vídeo e, finalmente, a criação da internet no final do século XX. (MORIN, 2001, p. 78)

A integração das tecnologias digitais no espaço escolar, em especial no caso do inglês como língua estrangeira, segundo Braga (2012), abre portas para o mundo fora da sala de aula além de oferecer insumo e imersão natural na língua, criando oportunidades individuais e coletivas de desenvolvimento das habilidades de leitura e escrita, fala e compreensão oral. O mesmo autor explica que a grande revolução no uso da internet foi o aparecimento da web a qual permitiu que professores e alunos de línguas estrangeiras passassem a ter acesso à produção cultural de outros países e a falantes dos diversos idiomas em salas de chat, listas de discussões e fóruns. Apesar das inúmeras atividades que podem ser feitas em um computador fora de rede, como editar textos, slides e planilhas, pode-se dizer que para o ensino e aprendizagem da língua inglesa, o uso dos recursos da internet é imprescindível, já que a web nos oferece materiais diversos e diversificados.

De acordo com Araujo (2016), um dos maiores fenômenos comunicativos que chega hoje às salas de aula são as redes sociais, por meio das quais as pessoas se relacionam umas com as outras em ambientes virtuais, de acordo com as suas afinidades e os seus interesses. Os recursos tecnológicos podem auxiliar no processo de ensino e ampliar as capacidades intelectuais dos alunos, colocando à sua disposição uma grande quantidade de informação, assim como diversos ambientes e ferramentas (LOUREIRO, 2013). A internet, realmente, revolucionou o ensino. Por meio dela encontramos vários recursos para a aprendizagem de inglês como: sites para prática de listening, 
speaking, writing e reading, dicionários on-line, vídeos, músicas, livros digitais, blogs, cursos on-line, aplicativos, entre outros infindáveis recursos. Loureiro (2013) cita, ainda, os jogos e aplicativos como: Duolingo, Babel, Winner, Upmind, Toondoo etc.

Beaugrande (2016) sinaliza a importância em se investigar quais são os recursos tecnológicos que podem ser utilizados como facilitadores e aliados na aprendizagem de língua inglesa, relacionandoos às habilidades comunicativas de ouvir, falar, ler e escrever. Partindo desse objetivo, apresentamos alguns recursos, relacionando-os com as principais habilidades que podem ser desenvolvidas a partir de seu uso pelo aprendiz. No entanto, reconhecemos que todos colaboram para o aperfeiçoamento da língua como um todo e não apenas da habilidade a qual foi relacionado. A seleção dos recursos tecnológicos apresentados neste trabalho foi realizada através de uma pesquisa na internet e em artigos e capítulos que abordam o tema a qual seguiu os seguintes passos: pesquisa bibliográfica sobre tecnologia e ensino de língua inglesa, levantamento dos principais recursos citados, busca na internet dos recursos apontados e de novos recursos, exploração dos sites encontrados e análise do seu conteúdo, descrição dos sites e identificação da habilidade comunicativa a qual mais se destina. Os critérios usados para selecionar os recursos tecnológicos para análise levaram em conta a sua adequação para as aulas de inglês no Ensino Fundamental e Médio, considerando estudantes de nível básico e intermediário, bem como o aprendizado das quatro habilidades linguísticas. Além disso, privilegiamos os recursos de acesso gratuitos e os mais atualizados.

\subsection{Listening (escuta)}

Listening é a habilidade que consiste na captação e compreensão dos sons externos. É necessário aprender a escutar, identificar e entender o que está sendo dito. 0 seu desenvolvimento acontece de forma mais acentuada quando aumentamos os canais de entrada do idioma, isso é possível no momento em que o professor proporciona aos alunos atividades como ouvir músicas em inglês, assistir a filmes, ouvir pessoas fluentes falando e toda forma de contato oral possível com a língua inglesa.

O audiolivro é um importante recurso para o desenvolvimento da habilidade de ouvir, pois pode ser utilizado em sala de aula ou em atividades extraclasse, o que possibilita 0 aprendizado do conteúdo gravado, mesmo quando o estudante está desempenhando outras atividades, também o permite ouvir várias vezes o áudio, o que é fundamental em práticas de aprendizagem. 
Há alguns sites como Free Classic Audio Books³ ${ }^{3}$ Learn Outl Loud ${ }^{4}$, Storynory 5 e Digital book ${ }^{6}$ que disponibilizam gratuitamente 0 acesso a audiolivros com conteúdo em inglês, proporcionando aos aprendizes que ampliem seus conhecimentos.

O site Colingo ${ }^{7}$ é ideal para os alunos aprenderem inglês com americanos nativos, a partir de aulas que acontecem através do Hangout, videoconferência do Google, que ajudam a praticar a fala e a compreensão auditiva. O English Speeches ${ }^{8}$, canal do YouTube, também tem como objetivo ajudar os alunos a praticar a audição e a leitura enquanto assistem a famosos discursos com legendas.

Uma maneira divertida de aprender e melhorar as competências linguísticas dos alunos pode ser através dos vídeos musicais no site Lyrics Training ${ }^{9}$, que possui um modo especial de karaokê que permite cantar e apreciar as letras completas. Além do treinamento ajudar a desenvolver a audição, melhora a capacidade de reconhecer sons e palavras.

\subsection{Speaking (fala)}

Speaking é a habilidade de falar que, por sua vez, está associada à habilidade de ouvir, pois grande parte do seu aprendizado se dá através da audição e da repetição dos sons, palavras e frases anteriormente ouvidas. Essa é sem dúvida a maior dificuldade para os alunos, porém é através da conversação e da interação oral que é possível obter a fluência. Através do uso do celular, o aluno pode gravar a sua voz e, em seguida, compará-la com a voz de um nativo. Essa é uma ótima técnica para desenvolver a fluência.

Alguns aplicativos como Duolingo ${ }^{10}$ prometem ao usuário o aprendizado de inglês com apenas cinco minutos por dia através de aulas, que mais parecem jogos, tanto para quem está iniciando com 0 básico como para quem deseja praticar a escrita e a fala. Ao utilizar o Duolingo em sala de aula, 0 professor pode tornar a aprendizagem mais interativa e divertida, pois o aluno recebe feedback imediato, isto é, correção para as atividades realizadas.

\footnotetext{
${ }^{3}$ Disponivel em: http://freeclassicaudiobooks.com/

${ }^{4}$ Disponivel em: https://www.learnoutloud.com/

${ }^{5}$ Disponivel em: https://www.storynory.com

${ }^{6}$ Disponivel em: $\underline{\text { https://www.digitalbook.iol }}$

7 Disponivel em: http://colingo.com/

8 Disponivel em: https://www.englishspeecheschannel.com/

${ }^{9}$ Disponível em: https://lyricstraining.com/

10 Disponivel em: https://pt.duolingo.com
} 
O aplicativo LinguaLeo ${ }^{11}$ foi desenvolvido para crianças, mas atrai adolescentes e até adultos com suas atividades interativas e divertidas que tornam a aprendizagem mais dinâmica. Antes de iniciar o seu uso, o estudante deve fazer um teste para avaliar o seu nível de conhecimento da língua. É um dos aplicativos para aprender inglês que mais oferece recursos: dicionário, exercícios de leitura, escrita e gramática, além de vídeos legendados em inglês.

Há alguns sites que ajudam os usuários na pronúncia das palavras, como 0 Google translate ${ }^{12} \mathrm{e}$ o Forvo ${ }^{13}$, um dos maiores guias de pronúncias do mundo. Além desses, o English Central ${ }^{14}$ possibilita que os alunos aprendam inglês com vídeos selecionados por assunto ou por nível de conhecimento. Através dessa plataforma, os alunos assistem a um vídeo por dia, recomendado com base em seu nível de conhecimento ou interesses. As palavras novas são aprendidas através do preenchimento dos espaços enquanto interagem com a linha do vídeo.

O Youglish ${ }^{15}$ é um excelente recurso para quem quer verificar a pronúncia e o contexto de uso das palavras através dos inúmeros vídeos com legendas disponibilizados pelo site. Por meio dele, o aluno pode assistir a um vídeo, escutar o áudio e ter dicas de como melhorar a sua fala. Ele também pode explorar determinado assunto de seu interesse através de uma busca em sua plataforma. É possível cadastrar-se e organizar os vídeos favoritos em uma biblioteca para ouvir quando e onde quiser, o que possibilita ao aluno acessá-los de qualquer lugar.

\subsection{Reading (leitura)}

Reading é a habilidade de ler e compreender os textos escritos, podendo ser desenvolvida através da prática assídua da leitura dentro e fora da sala de aula. O professor pode sugerir a leitura de textos sobre assuntos que interessam os alunos como em blogs, jornais internacionais e e-books. 0 site News in Levels ${ }^{16}$ é um ótimo recurso de leitura, com notícias do mundo todo para estudantes de inglês. Também oferece a opção de ouvir as notícias, fazer perguntas e ainda interagir via Skype, o que ajuda a desenvolver todas as habilidades comunicativas. Outros sites com notícias e uma grande diversidade de textos para praticar a leitura são Voice of America ${ }^{17}$ e BBC Learning English ${ }^{18}$.

\footnotetext{
11 Disponível em: https://lingualeo.com/pt

12 Disponível em: https://translate.google.com.br/?hl=pt-BR

13 Disponível em: https://pt.forvo.com/

${ }^{14}$ Disponível em: https://pt.englishcentral.com/videos

15 Disponível em: https://pt.youglish.com/

16 Disponível em: https://www.newsinlevels.com/

17 Disponivel em: https://www.voanews.com/

18 Disponivel em: https://www.bbc.co.uk/learningenglish/
} 
Infográficos podem ser utilizados no ensino e aprendizagem de língua inglesa para desenvolver a capacidade de leitura dos alunos. Muitas vezes a leitura é vista pelo estudante como algo monótono e cansativo, porém a utilização de infográficos facilita na compreensão do texto através dos seus elementos visuais os quais instigam a leitura. Há alguns sites gratuitos para a criação de infográficos: 0 Canva $^{19}$, o Piktochart ${ }^{20}$ e o Easel.ly ${ }^{21}$ são considerados os melhores sites.

No que se refere à leitura literária, a internet possibilita que os estudantes tenham acesso a um vasto número de e-books em sites como Project Gutenberg 22 com acervo de mais de 60.000 livros. Além dos inúmeros sites voltados para o ensino de inglês, explorar diversos gêneros textuais originais em inglês é uma forma de aproximar os alunos da escrita tanto literária quanto cotidiana. Gêneros como histórias em quadrinho, tirinhas, textos humorísticos, citações de famosos e campanhas publicitárias são populares entre os alunos e podem ser uma forma de iniciar a leitura a partir de textos mais curtos.

Cabe mencionar também a importância que os dicionários e tradutores on-line têm na compreensão leitora em (KARNAL; PEREIRA, 2013). É claro que se o estudante simplesmente traduzir o texto sem tentar compreendê-lo, não aprenderá a língua. No entanto, se utilizar essas ferramentas como estratégia de leitura, e de forma orientada pelo professor, poderá obter avanços significativos na sua aprendizagem. Uma das vantagens desses recursos é a sua rapidez de funcionamento. O Google Translate, por exemplo, possui uma extensão que pode ser instalada no navegador, ela permite que 0 leitor veja a tradução e a pronúncia de palavras e frases dentro do site original, sem precisar acessar 0 tradutor em outra janela. Assim, o aprendiz economiza tempo e pode investi-lo em novas leituras e aprendizagens.

\subsection{Writing (escrita)}

Writing consiste na habilidade de escrita a qual está inter-relacionada com a habilidade de leitura, uma vez que ambas se interconectam no processo de aprendizagem da língua inglesa. Portanto, ler auxilia no desenvolvimento da língua, especialmente, na aquisição de vocabulário e das estruturas gramaticais mais complexas presentes na modalidade escrita. Mas não basta ler, é preciso praticar habitualmente a escrita para que ela seja desenvolvida. 0 aprimoramento constante da escrita necessita

\footnotetext{
19 Disponível em: https://www.canva.com/pt_br/criar/infografico/

20 Disponível em: https://piktochart.com

21 Disponivel em: https://www.easel.ly/create/

22 Disponível em: https://www.qutenberg.org/
}

LínguaTec, Instituto Federal de Educação, Ciência e Tecnologia do Rio Grande do Sul, Bento Gonçalves v. 6, n. 1, p. 16-33, jun. 2021. 
do auxílio de um leitor/escritor mais experiente que possa ler o texto produzido e indicar os pontos a serem melhorados.

Além do auxílio do professor, os alunos também podem buscar leitores estrangeiros. Uma maneira de praticar a escrita, por exemplo, é fazendo amizade com pessoas de outros países nas redes sociais e praticando em chats. Apesar de ser uma escrita informal, é possível que o estudante desenvolva inúmeras habilidades linguísticas e comunicativas. Sites de penpal virtuais, como o Penpal Schools ${ }^{23}$, e de aprendizagem colaborativa de línguas como Tandem ${ }^{24}$, no qual você ensina a sua língua e aprende uma língua estrangeira, podem ser importantes locais para se buscar interações por meio da escrita ou da fala.

Um importante aliado para os alunos na escrita é o site Grammarly ${ }^{25}$, que ajuda a eliminar erros e encontrar as palavras mais adequadas para se expressar. É uma ferramenta avançada de correção ortográfica e gramatical que ajuda a evitar erros ao escrever em inglês no navegador. O blog Manual Grammarly 26 oferece uma série de dicas sobre gramática, funcionando como um guia com perguntas e erros gramaticais mais comuns. Além disso, possui uma seção sobre pontuação e, através do uso de gráficos, mostra a conjugação verbal e apresenta conceitos gramaticais de uma nova maneira visual.

Outro site a ser destacado é o Write\&improve ${ }^{27}$ da Cambridge, ele propõe tarefas de escrita de acordo com o nível de conhecimento apontado pelo aprendiz. Após concluir a sua escrita, o aprendiz a submete à avaliação do programa que aponta o que pode ser aprimorado.

O Kaplan Blog28 é um site destinado a auxiliar os alunos na aprendizagem de gramática e inglês situacional, de maneira mais conversacional e não necessariamente organizados por categoria, gramática e pontuação. Através de gráficos, imagens e explicações detalhadas, o blog se concentra em lições gramaticais específicas para cada postagem, sendo um excelente recurso a ser utilizado. Além disso, o blog oferece conselhos sobre o uso do inglês para viagens, estudos e desenvolvimento de carreira, tornando-o um recurso valioso para os alunos de inglês.

Os recursos apontados até aqui podem nos guiar e direcionar na busca de aperfeiçoamento de uma determinada habilidade. Contudo, o aprendizado da língua deve ser entendido de forma integrada, ultrapassando inclusive as habilidades linguísticas e se ampliando de forma a alcançar outras habilidades como as pragmáticas, culturais e sociais. É fundamental que essas habilidades sejam desenvolvidas em

\footnotetext{
${ }^{23}$ Disponível em: https://www.penpalschools.com/pt.html

24 Disponível em: https://www.tandem.net/

25 Disponível em: http://www.grammarly.com/com

26 Disponível em: https://www.grammarly.com/blog/

27 Disponivel em: https://writeandimprove.com/

28 Disponível em: https://www.kaplaninternational.com/br/blog/
} 
sincronia. O YouTube é uma excelente ferramenta para auxiliar os professores em sala de aula, pois permite o acesso a vídeos de diversos conteúdos. Ademais, é um instrumento que faz parte do universo e da linguagem do aluno. $O$ site YouTube disponibiliza vários canais para a aprendizagem da língua inglesa. Através de vídeos com professores ou com nativos, os alunos podem aprender sobre determinado assunto conciliando duas propostas, a prática da língua inglesa e os conteúdos úteis para a vida.

Há diversos canais que proporcionam uma aprendizagem complementar às aulas de língua inglesa. O canal The School of Life 29 disponibiliza vídeos curtos, com duração média de dois minutos, narrados em inglês britânico, com falas pausadas, acompanhadas por imagens ilustrativas. Trata de diversos temas ligados à filosofia, trabalho, comportamento e relacionamentos.

Os canais Winner ${ }^{30}$ e Ask Jackie ${ }^{31}$, além de tirar dúvidas sobre expressões, palavras e pronúncia, possuem uma playlist especial para que, quem é totalmente iniciante no idioma, possa acompanhar as aulas em uma sequência lógica de aprendizado. Eles também apresentam os hábitos e a cultural dos norte-americanos, fazendo comparações com os costumes brasileiros.

Alguns canais possuem uma atenção especial para a gramática e a pronúncia correta. $\mathrm{O}$ English with Jennifer ${ }^{32}$ é um dos canais mais completos para escrever, ler e falar em inglês, com aulas em inglês dinâmicas e bem explicadas. $O$ Small Advantages ${ }^{33}$ é uma ótima opção para aprender inglês com um nativo norte-americano fluente em língua portuguesa através de vídeos divertidos. Esse canal pode motivar os alunos a aprender inglês, pois nele o americano Galvin relata como aprendeu a falar português por conta própria e traz reflexões importantes sobre a experiência de aprendizado da nova língua. Os alunos, ao observarem as dificuldades de Galvin com o português, possivelmente passem a perceber 0 erro como natural quando ao tentar se comunicar em uma língua estrangeira.

Além do YouTube, que se destaca na variedade de materiais, os jogos eletrônicos também são ferramentas que podem ser utilizadas para fins didáticos. O professor pode selecioná-los de acordo com os conteúdos ensinados. Eles auxiliam na construção do conhecimento e desenvolvimento de habilidades. Os jogos educativos têm um papel lúdico porque estimulam a motivação dos alunos que, por sua vez, é um fator determinante para qualquer aprendizagem. Eles auxiliam no desenvolvimento, especialmente, do vocabulário na língua adicional, sendo grandes aliados na aprendizagem de língua inglesa, já que sem sair da comodidade de sua casa, o aluno pode ter acesso a conteúdos de forma

\footnotetext{
${ }^{29}$ Disponível em: https://www.youtube.com/user/schooloflifechannel

30 Disponível em: https://www.youtube.com/user/es/winner

31 Disponível em: https://www.youtube.com/channel/UCsl67ypZHHVoatvxzLBiNvg

32 Disponível em: https://www.youtube.com/user/JenniferESL

33 Disponível em: https://www.youtube.com/channel/UCskEPRzGIsYHs_a5SJyCXag
} 
informal e descontraída. Por meio dos jogos, os professores podem explorar novas possibilidades de ensino e aprendizagem.

Sem dúvida, as TICs trouxeram benefícios para alunos e professores no ensino e aprendizagem de línguas, mas é importante ressaltar que, se mal utilizadas, elas podem dispersar a atenção dos alunos para outros assuntos não relacionados aos conteúdos ensinados. A utilização dos recursos tecnológicos mediada pelo professor beneficia a construção dos conhecimentos de forma significativa.

Novos recursos surgem a cada dia e os estudantes são sedentos por novidades, já que as empresas que comercializam tecnologia criam constantemente a expectativa pelo novo. Todos querem conhecer e usar os recursos da moda. No entanto, quando o objetivo é aprender inglês, os estudantes carecem de orientação. É fácil se perder diante da infinidade de recursos, assim, o professor deve atuar como mediador, orientando e indicando os melhores caminhos de acordo com os objetivos e as necessidades de cada aprendiz. Esse é o tema que será aprofundado na próxima seção.

\section{0 papel do professor mediador}

Considerando a variedade e a qualidade dos recursos tecnológicos disponíveis para o ensino de língua inglesa, é evidente que o professor necessita também se tornar um profissional mais consciente e mais preparado para as transformações sociais e inovações tecnológicas. O papel do professor é fazer a mediação entre o estudante e o objeto de aprendizagem, é preciso tornar o conhecimento acessível ao entendimento dos discentes, para gerar aprendizagens significativas.

Conforme Coll (2002), a aprendizagem significativa está relacionada com a construção de significados como parte central do processo de ensino e aprendizagem. $\mathrm{O}$ aluno aprende um conteúdo ou uma explicação quando consegue atribuir-lhe significados. Para isso, o professor deve abordar temas atuais e assuntos interessantes em sala de aula. É necessário que o docente avalie os interesses e a faixa etária dos aprendizes a fim de introduzir os conteúdos.

$O$ aluno é o elemento principal no processo de ensino e aprendizagem, tendo como mediador do conhecimento o professor, o qual deve estar constantemente refletindo e construindo as suas práticas educativas. O grande desafio do professor mediador é aliar as tecnologias à sala de aula. Os recursos tecnológicos devem ser testados previamente pelos professores para que verifiquem quais são os seus potenciais usos, benefícios e possíveis dificuldades. Após conhecê-los e usá-los, eles podem ser apresentados gradativamente aos alunos.

Nesse processo, o planejamento mostra-se fundamental. Planejar exige do professor um 
trabalho de reflexão sobre o ensino e sobre a aprendizagem. Para desenvolver uma boa aula, é necessário que essa seja muito bem planejada, que tenha objetivos claros e precisos, bem como formas de avaliação que revelem se houve aprendizagem efetiva ao longo do processo. Para isso, cabe ao professor a busca de atividades que envolvam o aluno, dando-lhe a oportunidade de construir conhecimentos significativos. No planejamento, o professor deve considerar os conhecimentos prévios dos alunos, de forma que possa proporcionar a interação entre os conhecimentos prévios e os novos (CRYSTAL, 2003). Para isso, a avaliação diagnóstica é uma ferramenta valiosa, uma vez que permite a verificação do nível de conhecimento linguístico e, pode ainda incluir, questões voltadas para a identificação do perfil dos alunos.

O professor deve avaliar e diagnosticar com o objetivo de identificar os conhecimentos prévios dos estudantes, que podem ter sido construídos na escola ou em qualquer atividade cotidiana, para ensiná-los a partir daquilo que eles já sabem. Essa não é uma tarefa muito simples, mas é a essência da aprendizagem significativa. Deve-se começar fazendo um levantamento do que cada aluno já sabe sobre o novo conteúdo que será estudado. Através desse mapeamento inicial, o professor pode introduzir os novos conteúdos, incentivando os alunos a estabelecerem relações entre o que já sabem e o que irão aprender. Os conhecimentos prévios dos alunos auxiliam o professor a se planejar para conduzir as aulas de maneira a auxiliá-los em suas dificuldades de aprendizagem. Essa avaliação pode ser feita rápida e facilmente por meio de sites que disponibilizam ferramentas para se construir quizzes, palavras cruzadas, caça-palavras, entre outras atividades.

A aprendizagem significativa se caracteriza pela interação entre os novos conhecimentos e 0 conhecimento prévio do aluno. Nessa interação, os novos conhecimentos adquirem significado para 0 sujeito e os conhecimentos prévios adquirem novos significados ou maior estabilidade cognitiva. A avaliação mediadora se desenvolve em benefício do educando e dá-se, fundamentalmente, pela proximidade entre quem educa e quem é educado (HOFMANN, 2000). A avaliação mediada pelo professor é baseada no diálogo e na aproximação entre professor e aluno de forma que as práticas de ensino sejam repensadas e modificadas de acordo com a realidade sociocultural de seus aprendizes.

Através de uma prática reflexiva, o professor tem a oportunidade de conhecer os seus alunos e identificar a melhor maneira de promover a aprendizagem, sempre levando em conta os seus conhecimentos anteriores. A avaliação mediadora visa conhecer, não apenas para compreender, mas também para promover ações em benefício dos educandos.

Beaugrande (2016) alerta para o fato de que o educador deve assumir uma postura de "desacomodação" diante desse contexto, ou seja, o professor deverá apostar nesses recursos de forma 
construtiva ao fazer uso deles em sala de aula. A atualização do educador em relação às tecnologias deve ser considerada tão importante quanto a sua formação acadêmica (ARAÚJO, 2016). É necessário que o professor esteja atento para acompanhar a evolução desses recursos, mantendo-se em constante aprimoramento. Além dos conhecimentos linguísticos e pedagógicos, é importante que desenvolva conhecimentos tecnológicos para que, ao ensinar, o professor sinta-se confortável, estabelecendo, assim, objetivos claros quando utilizar os recursos tecnológicos em suas aulas.

Beaugrande (2016) explica que a ideia de utilizar recursos tecnológicos e midiáticos parte do princípio de que a interatividade passa a ser entendida como uma maneira de o estudante ter uma participação ativa, de tal forma que consiga contribuir para o seu aprendizado. Para isso, o educador deverá ter consciência da importância da qualidade da interação que ocorre entre ele e os alunos, interação essa que pode favorecer a aprendizagem e o desenvolvimento das competências comunicativas dos educandos.

Segundo Leffa (1988), o material usado para a aprendizagem da língua deve ser autêntico e os diálogos devem apresentar personagens em situações reais de uso da língua. Dessa forma, ao introduzir as ferramentas tecnológicas na aula de inglês, o professor pode alterar o contexto, tornando-o atrativo e inovador. Todavia, não basta usar materiais autênticos disponíveis na internet se o professor continuar sendo o centro do processo de ensino. As atividades propostas devem mudar o foco do professor para 0 aluno, dando aos aprendizes maior autonomia e, até mesmo, responsabilidade pelo processo de ensino e aprendizagem.

O computador não é mais ou menos importante do que o aluno ou o professor (ARAÚJO, 2016); quando usado na aprendizagem ele é apenas um instrumento. Nessa perspectiva, pode-se afirmar que o professor exerce papel fundamental no processo de aquisição de uma nova língua. Cabe a ele ter domínio dos conteúdos e desenvolver as habilidades específicas para desempenhar adequadamente 0 seu papel e utilizar uma metodologia de ensino adequada ao perfil de seus alunos.

Os recursos tecnológicos sozinhos não revolucionam a aprendizagem e nem o ensino, por isso faz-se necessário que o professor tenha formação para utilizar esses recursos de forma apropriada, caso contrário, as tecnologias em sala de aula podem não ser benéficas. Segundo Demo:

O fundamental é saber transformar informação em conhecimento próprio através de procedimentos adequados de aprendizagem. $O$ acesso fácil às informações é uma das vantagens da tecnologia, contudo, para que ela favoreça a aprendizagem é necessário o professor como mediador destas informações. Pode-se afirmar que os avanços tecnológicos e a implementação de ferramentas de apoio aos processos de ensino convencional têm favorecido significativamente uma melhora nos métodos de ensino e aprendizagem (DEMO, 2007, p. 91-92). 
Nesse contexto, o professor atua como mediador e pode, até mesmo, fazer uma espécie de curadoria, traçando os percursos e indicando os recursos mais adequados de acordo com as necessidades e dificuldades dos seus alunos.

Conforme Chalita (2001), o computador nunca substituirá o professor, por mais evoluída que seja a máquina, por mais que a robótica profetize evoluções fantásticas, há um dado que não pode ser considerado: a máquina reflete e não é capaz de dar afeto, de passar emoção, de vibrar com a conquista de cada aluno. Destaca-se nessa passagem a importância da conexão entre professor e aluno, é essa proximidade e interação humana que proporcionam uma experiência de aprendizagem única que não pode ser reproduzida pela máquina. Durante esses longos meses de ensino remoto ao qual fomos forçados devido à pandemia provocada pelo COVID-19, mais do que nunca percebemos que, apesar da tecnologia ser importante, o professor é insubstituível. A tecnologia nos auxilia, mas quem realmente ensina é o professor.

\section{Aprendizagem autônoma}

Os estudos de Crystal (2003), anexos à teoria de Beaugrande (2016), identificam que os recursos tecnológicos podem ser utilizados na aprendizagem autônoma de forma a complementarem as aulas de língua inglesa. É evidente que a tecnologia contribui para o desenvolvimento dos alunos, tornando a aprendizagem mais dinâmica, atrativa e autônoma.

A autonomia é fundamental no processo de aprendizagem, pois é ela que faz com que o aluno seja o agente de sua própria aprendizagem e não uma tábula rasa que se molda de acordo com as imposições dos métodos dos professores. Tornar o aluno autônomo em seu processo de aprendizagem significa atribuir a ele, ou compartilhar com ele, a responsabilidade pelas decisões relacionadas aos fatores que envolvem a aprendizagem, ou seja, definir objetivos, organizar conteúdos, escolher os métodos a serem utilizados, acompanhar como a aprendizagem está acontecendo e avaliar o que foi aprendido.

O desenvolvimento da autonomia dos educandos se dá a partir da criação de oportunidades em sala de aula. Cabe ao professor motivar seus alunos e dar ferramentas para que possam se tornar autônomos, utilizando estratégias e promovendo meios facilitadores de aprendizagem. A utilização das tecnologias através da internet contribui para o desenvolvimento do espírito crítico dos alunos, bem como permite experimentar novas formas de trabalho, o que auxilia na construção de conceitos, incentiva a interdisciplinaridade, desenvolve o sentido de cooperação e autonomia dos alunos. 
A aprendizagem autônoma pode ser descrita como uma forma de ensino amparada em três pilares principais: a) a tecnologia, fundamental para busca de conhecimento em diversas fontes; b) 0 acompanhamento, indispensável para compartilhar e discutir as soluções descobertas; e c) a liberdade, para que 0 aluno possa traçar seu próprio caminho rumo à sabedoria. Portanto, a aprendizagem autônoma não significa abandonar o aprendiz à própria sorte, mas dar-lhe mais independência com orientação.

$\mathrm{Na}$ aprendizagem autônoma, o aluno passa a ser responsável pela sua própria aprendizagem. Uma forma de incentivar essa autonomia é através do ensino híbrido o qual combina experiências presenciais e on-line por meio de tecnologias digitais tendo como principal objetivo promover uma reorganização do tempo e do espaço das aulas.

0 ensino híbrido ${ }^{34}$ nas aulas de língua inglesa tem como objetivo dar oportunidade de aprendizado para os alunos de acordo com as suas possibilidades, dando-lhes mais autonomia e liberdade. Conforme Christensen, Horn e Staker (2013), o ensino híbrido é um programa de educação formal no qual o aluno aprende, pelo menos em parte, por meio do ensino on-line. A utilização do ensino híbrido busca o desenvolvimento da autonomia dos educandos, o que permite que possam compartilhar conhecimentos, utilizando tecnologias digitais como aliadas nesse processo. Isso faz com que os estudantes modifiquem as suas posturas em relação à aprendizagem e à construção dos seus conhecimentos.

Escolas de idiomas já utilizam essa modalidade há muito tempo, complementando as aulas presenciais por meio de atividades em suas plataformas on-line as quais substituíram os livros de exercícios (workbooks), porém, com a vantagem de terem correção automática, fácil acompanhamento pelo professor e inúmeras outras ferramentas para intensificar a aprendizagem. $\mathrm{O}$ ensino híbrido pode ser uma boa alternativa para as escolas públicas, uma vez que auxilia na superação de problemas como a baixa carga horária prevista nos currículos para o ensino de inglês e o grande número de alunos em sala de aula. Por meio dele, é possível ampliar a carga horária com as atividades on-line e fazer 0 acompanhamento aluno a aluno. No entanto, para a implementação dessa modalidade de ensino, as escolas e os estudantes ainda carecem de maior acesso à tecnologia, como internet e computadores, e a plataformas que permitam esse acompanhamento individual.

Mercado (2002) explicita ainda que, além de contribuir para o aprimoramento das habilidades linguísticas do aprendiz, os recursos digitais podem também ser de grande valia para o desenvolvimento

${ }^{34} \mathrm{O}$ Ensino Híbrido combina o uso da tecnologia digital com as interações presenciais, visando à personalização do ensino, é um modelo possível para facilitar a combinação, de forma sustentada, do ensino on-line com o ensino presencial. 
de sua consciência intercultural. Nesse sentido, o acesso à internet tanto pode consolidar os conhecimentos da língua-alvo, como também aqueles relativos à cultura-alvo.

Conforme Vygotsky (1984), o ser humano é um ser social que se constrói através da interação que estabelece com os outros indivíduos, mediada pela sua cultura. Logo, ele necessita ser motivado a buscar o conhecimento para o seu próprio desenvolvimento como indivíduo. A aprendizagem torna-se mais significativa quando o estudante se sente responsável por buscar e produzir conhecimento. Sendo assim, o professor, ao incentivar a aprendizagem de forma autônoma, conduz 0 estudante a maior independência de forma que não apenas o professor busque alternativas para ensinar, mas o aluno passe a buscar e a desenvolver suas próprias estratégias para aprender.

A internet proporciona aos alunos mais autonomia e, segundo Mercado (2012), também favorece a interatividade entre aprendizes e professores que já podem se comunicar, trocar informações, executar tarefas em grupo, receber feedback on-line e até mesmo estreitar laços de conhecimento e amizade. A utilização de recursos tecnológicos na educação auxilia não só na melhora da aprendizagem, bem como no desenvolvimento da autonomia dos alunos, ou seja, cabe a eles a responsabilidade de procurar atividades por si só, as quais não dependem de um professor para serem realizadas. $O$ futuro do ensino de idiomas tende a ser cada vez mais personalizado às necessidades específicas de cada aluno.

Antes da internet, a comunicação e a interação do aprendiz de línguas se limitavam ao ambiente da sala de aula e aos seus indivíduos, o professor e os colegas. Com o surgimento da internet e das redes sociais, as possibilidades de interação na língua inglesa são incontáveis. Assim, o professor deixa de ser o único facilitador do processo de ensino e aprendizagem. É preciso que ele assuma esse novo papel e, não apenas assuma, mas tire proveito disso. Mostrar aos alunos os recursos disponíveis para a aprendizagem autônoma e incentivar o seu uso é uma forma de despertar o seu interesse e intensificar o seu aprendizado.

Sabemos que a aquisição de uma língua depende de uma exposição massiva e contínua ao seu uso, o que pode ser alcançado facilmente com a utilização de recursos disponíveis na internet. Eles não substituem a sala de aula e o professor, porém, ampliam as possibilidades de aprendizagem e o papel protagonista do aprendiz. Todos os recursos tecnológicos citados neste trabalho podem ser utilizados também de forma autônoma, contribuindo para o desenvolvimento de seus aprendizes.

\section{Considerações finais}


Apesar de muitas escolas e professores utilizarem recursos tecnológicos no ensino e aprendizagem de língua inglesa, a trajetória do uso da tecnologia nessa área não tem sido linear e, mesmo nos dias de hoje, o acesso a esses recursos não está ao alcance de todos. Percebe-se, no entanto, a importância da utilização de recursos tecnológicos para o desenvolvimento do ensino e aprendizagem da língua inglesa, ao proporcionar ferramentas que, se bem utilizadas, tornam as aulas mais dinâmicas e interessantes.

A tecnologia é uma aliada do processo de ensino e aprendizagem, por isso, além do conhecimento linguístico e pedagógico, é importante também desenvolver o conhecimento tecnológico para que, ao ensinar, o professor sinta-se seguro na utilização desses recursos. As ferramentas digitais que o educador tem à disposição são indispensáveis, pois possibilitam a construção de uma aprendizagem mais significativa e autônoma. A tecnologia também pode viabilizar novas formas de ensinar como a metodologia baseada em tarefas e projetos, atividades que possibilitem a abordagem de temas contemporâneos e integrem as diversas habilidades envolvidas na aquisição da língua.

Certamente, a inserção das tecnologias é uma tarefa desafiadora, uma vez que implica não apenas no seu acesso, ainda restrito em muitas escolas, como também na mudança dos papéis do professor e do estudante, o que, consequentemente, altera diversos processos como o planejamento e a avaliação. Ao se colocar como mediador da interação entre o estudante e o objeto de aprendizagem, o professor pode tornar o conhecimento mais acessível ao entendimento para, assim, gerar aprendizagens significativas e desenvolver a autonomia dos alunos.

Por fim, embora não seja o objetivo deste artigo, não podemos deixar de refletir, brevemente, sobre o que o ensino remoto ao qual fomos impelidos durante a pandemia do coronavírus nos revelou sobre a tecnologia e a educação. Se, por um lado, houve grande desenvolvimento no letramento digital de educadores e educandos; por outro lado, muitos ficaram à margem desse processo, o que revelou a enorme desigualdade que existe no país no que tange ao acesso à tecnologia, não apenas por parte dos alunos, mas também por parte das escolas e dos professores. Portanto, antes de falar em incluir a tecnologia em sala de aula, cabe refletir sobre a necessidade urgente de se promover a inclusão digital de todos os envolvidos no processo educacional. Dar acesso à educação hoje é mais do que garantir a matrícula na escola, para democratizar o conhecimento precisamos democratizar 0 acesso a ele por meio da tecnologia.

\section{Referências}


ARAÚJO, A. F. Integrando as quatro habilidades linguísticas no Ensino de Língua Inglesa. In: III CONEDU CONGRESSO NACIONAL DE EDUCAÇÃO, 2016, Natal, RN. Anais do III Conedu Congresso Nacional de Educação. Natal: Editora Realize, 2016. p. 1-14. Disponível em:

http://www.editorarealize.com.br/revistas/conedu/trabalhos/TRABALHO_EV056_MD1_SA16_ID4607_1 4082016134318.pdf. Acesso em: 02 dez. 2020.

BARBOSA, L. S. R.; SILVA, A. C. T. A educação infantil proposta por meios de comunicação: Relatório de projeto de iniciação cientifica PIC. Universidade Estadual de Maringá, 2009.

BRAGA, L. P. Avanços tecnológicos na educação. São Paulo: Ática, 2012.

BEAUGRANDE, R. O Ensino da Língua Inglesa e as tecnologias. São Paulo: Ática, 2016.

CHALITA, G. Educação: a solução está no afeto. São Paulo: Editora Gente, 2001.

CHRISTENSEN, Clayton M.; HORN, Michael B.; STAKER, Heather. Ensino Hibrido: uma Inovação Disruptiva?: Uma introdução à teoria dos híbridos. 2013. Disponível em: https://www.pucpr.br/wpcontent/uploads/2017/10/ensino-hibrido_uma-inovacao-disruptiva.pdf. Acesso em: 15 out. 2020.

CRYSTAL, D. Estratégias no Ensino da Língua Inglesa. São Paulo: Ática, 2003.

DEMO, P. Porvir: Desafios das linguagens do século XXI. Curitiba: Imbpex, 2007.

HOFFMANN, J. M. L. Avaliação Mediadora: uma prática em construção da pré-escola à universidade. Porto Alegre: Educação \& Realidade, 2000.

KARNAL, A. R.; PEREIRA, V. W. Compreensão leitora e o uso do tradutor eletrônico nas aulas de inglês instrumental (ESP). Revista X, v. 1, p. 62-80, 2013.

LEFFA, V. J. Aprendizagens de línguas mediada por computador. Pelotas: Educat, 2006. Disponível em: www.leffa.pro.br/textos/trabalhos/B_Leffa_CALL_HP.pdf. Acesso em: 02 nov. 2020.

Metodologia do ensino de línguas. In: BOHN, H. I.; VANDRESEN, P. Tópicos em linguística aplicada: o ensino de línguas estrangeiras. Florianópolis: Ed. da UFSC, 1988. p. 211-236. Disponível em: http://www.leffa.pro.br/textos/trabalhos/Metodologia_ensino_linguas.pdf. Acesso em: 10 out. 2020.

LOPES, D. V. As Novas Tecnologias e o Ensino de Línguas Estrangeiras. Revista Científica Tecnologus, v. 1 1, 2012. 2 Disponivel em: http://www.unibratec.edu.br/tecnologus/wpcontent/uploads/2012/08/tecnologus_edicao_06_artigo_01.p df. Acesso em: 05 nov. 2020.

LOUREIRO, A. P. V. Aprender inglês como segunda língua - a importância do domínio de outras línguas num mundo globalizado. Lisboa: Universidade Lusófona de Humanidades e Tecnologias. Dissertação de Mestrado, Instituto de Educação, Lisboa, 2013.

MERCADO, L. P. L. Novas tecnologias na educação: reflexões sobre a prática. Maceió: Edufal, 2012.

MORIN, E. Os sete saberes necessários à educação do futuro. 3. ${ }^{a}$ ed., São Paulo: Cortez, 2001. 
VYGOTSKY, L. S. A formação social da mente. Rio de Janeiro: Martins Fontes, 1984.

VYGOTSKI, L. S. Obras Escogidas. Traducción de Lydia Kuper. Madrid: A. Machado Libros, 2006. Tomo IV.

Data de submissão: 15/02/2021. Data de aprovação: 16/04/2021. 